\title{
When A SPOONFUl OF SUGAR DOESN'T HeLP THE MEDICINE Go DOWN: INFORMED CONSENT, MENTAL ILLNESS, AND MORAL AgENCY
}

\author{
Erin Talati*
}

\section{TABLE OF CONTENTS}

INTRODUCTION

I. ALL INTERVENTIONS BETWEEN HEALTH CARE PROVIDER AND

PATIENT REQUIRE INFORMED CONSENT

A. The Informed Consent Requirement Follows a Dissonant History of Deference to Physician Judgment.

B. General Requirements of Adequate Informed Consent Include

Competence, Knowledge, and Voluntariness

1. A determination of competence should be made prior to disclosure of information

2. The knowledge requirement correlates with the physician duty of disclosure

3. The requirement that informed decisions be voluntary provides the last protection for patients

II. MENTAL ILLNESS RAISES SPECIAL CONSIDERATIONS WHEN CONTEMPLATING INFORMED CONSENT.

A. Many Individuals with Mental Illness may not have the Requisite

Capacity to Consent

B. Knowing How Far the Duty to Disclose Extends Becomes

Especially Difficult When Dealing with Mental Illness.

1. Treatments for mental illness are incompletely developed and carry with them the risk of significant adverse effects ....... 186

2. The physician perspective standard provides a great deal of deference in disclosure to patients

3. The "patient centered" materiality standard inadequately accounts for variability in symptoms of mental illness ...... 190

C. Individuals with Mental Illness are Particularly Vulnerable to Coercion that may Make Consent Involuntary.

III. WHERE INFORMED CONSENT IS LEGALLY INEFFECTIVE BECAUSE OF COERCION, THE CONDITIONS WHICH MADE IT COERCIVE ALSO MAKE IT UNETHICAL

* J.D. cum laude, 2007, University of Pennsylvania Law School, MD, M. Bioethics, 2007, University of Pennsylvania School of Medicine. Housestaff, University of Chicago Hospitals. The author thanks with appreciation Karyn Brudnicki for her careful editing skills and thoughtful suggestions on an earlier draft of this manuscript. All errors and opinions are mine. 
A. Informed Consent Respects the Principle of Autonomy

$B$. Theories of Biomedical Ethics are Based on Respect for the Individual and Generally Function in Concert with Autonomy.

1. Beneficence.

2. Nonmaleficence ........................................................... 195

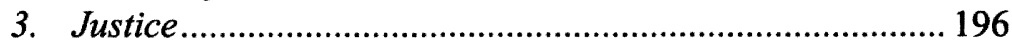

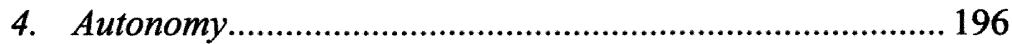

C. Beyond Traditional Principles of Biomedical Ethics: Moral Agency in the General Community Still Requires Autonomy... 197

\section{ABSTRACT}

When a patient disagrees with a treatment recommendation or requests a treatment not specifically recommended for the particular situation under consideration, medical teams often turn to ethicists. The ethical inquiry usually begins in the same place: does the individual in question have the decisional capacity to refuse or request whatever is at issue? Really, this question asks whether this individual has the moral agency to act in the way she is acting. Mental illness complicates the analysis.

When the legal requirements for consent cannot be met or circumstances render it necessary for a mentally ill individual to be medicated, the requirement for consent is suspended. In other situations, it is questionable whether ordinary consent by an individual with mental illness is really informed despite our reliance on these decisions in determining whether an individual has a place in a particular moral community. Because a large emphasis in criminal law is placed on the mentally ill individual taking responsibility for her illness through medication compliance, ${ }^{1}$ compliance with treatment might inform whether we view her choices as moral. If the validity of consent to treatment comes into question, however, an expectation to conform to a treatment regimen may itself be unethical. This Article concludes that consent obtained by conditioning moral standing on medication compliance is legally invalid due to coercion and ethically invalid because it undermines autonomy thereby undermining the very basis of moral agency. Treatment-absent valid consent in these situationsmay be ethical sometimes, but should not be justified on the basis of informed consent.

1. See generally Michael D. Slodov, Criminal Responsibility and the Noncompliant Psychiatric Offender: Risking Madness, 40 CASE W. RES. 271 (1990) (arguing that an offender who has been noncompliant with a prescribed medication regimen should not be allowed to subsequently claim an insanity defense because of her failure to ameliorate the effects of her illness). 


\section{INTRODUCTION}

In the medical world, we call into question the individual's moral agency on a regular basis. Almost any time a patient disagrees with a treatment recommendation or requests a treatment not specifically recommended for the particular situation under consideration, medical teams often turn to ethicists for help. The ethical inquiry usually begins in the same place in every case: does the individual in question have the decisional capacity to refuse or request whatever is at issue? Actually, this question asks whether this individual has the moral agency to act in the way she is acting. Mental illness greatly complicates the analysis.

Mental illness raises a number of concerns that motivate different approaches to its treatment. A predicate to any treatment in the medical context is obtaining the informed consent of the patient. In some situations, when the legal requirements for consent cannot be met or circumstances render it necessary for a mentally ill individual to be medicated for the safety of others, this requirement of consent is suspended, and such situations are not the focus of this discussion. For the mentally ill patient, in other situations, however, it is questionable whether ordinary consent is really informed despite our reliance on these decisions in determining whether an individual has a place in a particular moral community. Because a large emphasis in criminal law is placed on the mentally ill individual taking responsibility for her illness through medication compliance, ${ }^{2}$ conformity (or non-conformity) to a treatment regimen might inform whether we view his or her choices as moral or ethical. When one considers the fact that it may be a rational decision to forego treatment for mental illness, ${ }^{3}$ the question arises whether consent agreeing to a treatment regimen can be informed. If the validity of the consent to treatment comes into question, one must also consider whether the expectation to conform to a treatment regimen is itself unethical.

This Article asks whether it is legally or ethically valid to grant moral agency to an individual with mental illness based on whether she assumes responsibility for her mental illness, particularly through compliance with a recommended treatment regimen. Part I of this Article discusses the history and legal requirements of the informed consent doctrine. Part II considers informed consent in the context of mental illness and concludes that treatment of informed consent in mentally ill persons must be regarded even more stringently than in the traditional context because of increased vulnerability of this population to coercion. Part III contemplates whether consent that may be considered

2. See generally id.

3. See Jessica L. MacKeigan, Note, Violence, Fear, and Jason's Law: The Needless Expansion of Social Control Over the Non-Dangerous Mentally Ill in Ohio, 56 CLEV. ST. L. REV. 739, $752 \mathrm{n} .97$ (2008) ("A decision not to comply [with medication] may be more indicative of an aversion to medication side effects than to a lack of competence or an inability to make an informed treatment decision."). 
legally invalid on the basis of coercion is ethical, finding ultimately that equating moral standing in a community with whether or not a mentally ill individual chooses to comply with recommended treatment exerts an undue influence on that individual's ability to give informed consent. Moreover, failure to obtain valid informed consent undermines autonomy, and because autonomy is requisite for moral agency, any action which undermines autonomy will also undermine moral agency. The multi-step argument essentially concludes that conditioning moral standing in a community on a mentally ill individual's acceptance of a medication treatment regimen will itself undermine moral agency. Treatment, absent valid consent in these situations, may be ethical sometimes, but should not be justified on the basis of informed consent. This Article does not aim to imply that consent can never be obtained from individuals with mental illness nor that treatment is never appropriate in individuals whose consent cannot be voluntary, only to say that in these cases, rather than creating a fictional belief of consent, the criteria for involuntary treatment must be realized. ${ }^{4}$

\section{All Interventions Between Health CARe Provider AND Patient REQUIRE INFORMED CONSENT}

A long history of cases dealing with unauthorized acts by health care providers form the foundation for the modern concept of consent. Informed consent requires competence, knowledge, and voluntariness. ${ }^{5}$

\section{A. The Informed Consent Requirement Follows a Dissonant History of De- ference to Physician Judgment ${ }^{6}$}

Informed consent is now the cornerstone of any contact between a health care provider and a patient. The modern rule requiring informed consent for every medical intervention follows a long history of behaviors inconsistent with the stated requirements for consent. Thought to be a seminal case in informed

4. Involuntary treatment can only be imposed when due process is afforded to the individual being treated. See Washington v. Harper, 494 U.S. 210, 225-26 (1990) (requiring due process for involuntary medication of individuals with mental illness); Addington v. Texas, 441 U.S. 418, 427 (1979) (discussing the due process rights of individuals with respect to involuntary commitment). While assisted outpatient treatment statutes are not the focus of this Article, they too raise concerns about due process and have been challenged on these grounds, reaffirming the need for due process whenever true consent cannot be obtained for treatment. See In re K.L. 806 N.E.2d 480 (N.Y. 2004) (finding no due process violation in the application of the assisted outpatient treatment statute considered in that case); In re Urcuyo 714 N.Y.S.2d 862 (N.Y. Sup. Ct. 2000) (implying that forced medication without a finding of incapacity might violate due process).

5. See infra Part II.B. (discussing the elements of the informed consent doctrine).

6. For a general overview of informed consent history, see Joan L. O'Sullivan and Breck G. Borcherding, Informed Consent for Medication in Persons with Mental Retardation and Mental Illness, 12 HEALTH MATRIX 63, 66-69 (2002). 
consent jurisprudence, the 1914 Schloendorff v. Society of New York Hospital ${ }^{7}$ case held that unless a patient is unable to consent and an emergency intervention is necessary, any intervention by a physician done without consent constitutes assault. ${ }^{8}$ The court opined that, "[e]very human being of adult years and sound mind has a right to determine what shall be done with his own body.", The Schloendorff decision however, was arguably neither particularly novel nor especially effective in changing physician practice. The court's language was reminiscent of Justice Gray's earlier pronouncement in the Supreme Court's first impression on informed consent that, "[ $t]$ he right to one's person may be said to be a right of complete immunity: to be let alone." $"$ In addition, following the Schloendorff decision, little changed in the deference given to physicians in carrying out their duties.

During the 1950 s, the landscape finally began to change. Initially, cases during this period continued to be deferential to physician judgment. ${ }^{11}$ In 1957 ,

7. 105 N.E. 92 (N.Y. App. 1914). The patient in this case presented to the defendant hospital with abdominal complaints. Id. at 93 . A mass in the lower abdomen was appreciated on physical exam but could not be more fully characterized without a further invasive internal examination under anesthesia. $I d$. The plaintiff contended that she consented to such an examination but stipulated that there should be no operation. Id. When she awoke from anesthesia, a fibroid tumor had been removed. $I d$. She argued that the operation was performed with neither her knowledge nor consent. Id.

8. Id. at 93 ("' $[\mathrm{A}]$ surgeon who performs an operation without his patient's consent, commits an assault, for which he is liable in damages. This is true except in cases of emergency where the patient is unconscious and where it is necessary to operate before consent can be obtained.").

9. Id. The Schloendorff case is particularly notable because it involved harm resulting from active intrusion, "trespass" into the patient's body rather than "mere negligence." Id. Significantly, the court foretold an essential element of informed consent doctrine relevant to mental illness. The court stated that only those "of sound mind" could invoke this right of self determination regarding his body. Id. at 129.

10. Union Pac. R.R. v. Botsford, 141 U.S. 250, 251 (1891) (quoting THOMAS MCINTYRE COOLEY, A TREATISE ON THE LAW OF TORTS, OR, THE WRONGS WHICH ARISE INDEPENDENT OF CONTRACT 29 (Callaghan \& Company 2nd ed. 1888) (1880)) (internal quotations omitted). In this case, the court held that a woman could not be forced to undergo a surgical exam by physicians chosen by the railroad when she sued them for injuries sustained as a result of alleged negligence on the part of the railroad. See id. ("The single question presented by this record is whether, in a civil action for an injury to the person, the court, on application of the defendant, and in advance of the trial, may order the plaintiff, without his or her consent, to submit to a surgical examination as to the extent of the injury sued for. We concur with the Circuit Court in holding that it had no legal right or power to make and enforce such an order."). See also Louis Brandeis and Samuel Warren, The Right to Privacy, 4 HARV. L. REV. No. 5 (1890) (stating, while making an argument that a right to privacy exists, that "now the right to life has come to mean the right to enjoy life, - the right to be let alone").

11. See Kennedy v. Parrott, 90 S.E. $2 d 754,759$ (N.C. 1956) (holding that a surgeon who extended an operation beyond that for which consent had been obtained was not liable for injuries resulting from this extension because it was his duty to perform an operation consistent with good surgical practices and he was free to exercise his informed judgment as to what good practice required). But see Rogers v. Lumbermens Mutual Casualty Co., 119 So.2d 649, 652-53 (La. App. 2d Cir. 1960) (holding neither express nor implied consent for a surgeon to extend surgery in a non-emergent situation beyond what had been consented even if exercising good faith judgment in his performance). 
the "duty to disclose" was born in California, marking a departure from prior jurisprudence. 12 "A physician violates his [affirmative] duty [to disclose] to his patient and subjects himself to liability if he withholds any facts which are necessary to form the basis of an intelligent consent by the patient to the proposed treatment." In further describing this duty, the court announced a corresponding negative duty to refrain from, "minimiz[ing] the known dangers of a procedure or operation in order to induce his patient's consent."14 Recognizing that this expectation could place physicians in a situation in which patients might reject interventions involving little practical risk due to placing an excessive emphasis on the dangers associated with the procedure, the court concedes that "the patient's mental and emotional condition is important . . . and that in discussing the element of risk a certain amount of discretion must be employed consistent with the full disclosure of facts necessary to an informed consent."15 The duty to disclose included some degree of judgment on the part of the physician but in essence established, for the first time, that a patient had a right to an opinion and informed direction over her care. ${ }^{16}$ Balancing physician judgment with the requirement of consent requires the physician to understand the criteria essential for adequate informed consent so that she might know how to best take the patient's "mental and emotional condition" into account in meeting her duty.

\section{B. General Requirements of Adequate Informed Consent Include Compe- tence, Knowledge, and Voluntariness}

Informed consent combines the duty to disclose with a requirement that the consenting individual is capable of understanding the information pre-

12. See Salgo v. Leland Stanford Jr. Univ. Bd. of Trs., 317 P.2d 170, 181 (Cal. Ct. App. 1957) (holding a surgeon liable for performing a surgical procedure without informing the patient of what the procedure involved).

13. Id. at 181 .

14. Id.

15. Id. (emphasis added). This realization on the part of the court is important. This flexibility may be necessary for certain extreme situations which the court seems to contemplate where a particularly risk averse patient may refuse a treatment that could be lifesaving and has little probability of risk, however, the judgment component has potentially more significant risks, especially in the context of mental illness. It admits that mental conditions may influence a person's decision-making regarding medical interventions, but it does not explicitly acknowledge that this vulnerability permits a provider or other person who may have some authority over whether a mentally ill person is or is not medicated to have discretion in creating the picture she wants the mentally ill person to envision in order to ensure compliance with a medication regimen under the illusion that consent is present. See discussion infra Part II.B.2.

16. See Natanson v. Kline, 350 P.2d 1093 (Kan. 1960) (delineating further the physician responsibility to inform a patient regarding her care and seek input on her desired course of action); see also Ashcraft v. King, 228 Cal. App. 3d 604 (1991) (allowing greater patient involvement in care by placing conditions on consent); Restatement Second of Torts $\S 89(\mathrm{a})(2)$ (1965) (permitting conditions to be placed on individuals which limit the scope of consent). 
sented, requiring that the individual is competent, that she is free of undue influences in making the decision, and that her decision is voluntary. ${ }^{17}$

\section{A determination of competence should be made prior to disclosure of information}

Prior to disclosing risks and benefits attendant to any medical intervention, the physician must judge the capacity of the patient to give consent. ${ }^{18}$ The competency question must be resolved before determining whether a duty of disclosure has been met, because if incompetent, a patient by definition lacks the ability to logically understand and incorporate the knowledge disclosed, ${ }^{19}$ therefore making her consent necessarily invalid. ${ }^{20}$ Four commonly accepted components of competency include: "(i) ability to communicate a choice, (ii) ability to understand relevant information, (iii) ability to appreciate the nature of the situation and its likely consequences, and (iv) ability to manipulate information rationally."21 These factors, identified initially in a non-legal context, appear to influence judicial determinations of informed consent ${ }^{22}$ and can therefore be used as a standard against which a clinician may judge capacity and an observer may judge whether adequate consent was obtained.

17. Informed consent is a legally charged concept; although different disciplines may inform what constitutes valid consent, jurisprudence focuses on the three factors of competency, disclosure, and voluntariness. See Alan Meisel et. al, Toward a Model of the Legal Doctrine of Informed Consent, 134 AM. J. PsYCHIATRY, 285, 285 (1977) ("The components [of informed consent] consist of the precondition of voluntariness, the provision of information, the patient's competency and understanding, and, finally, consent or refusal.")

18. Because competence is a legally defined term, a finding of competency itself is generally left for court determination. A professional's judgment of capacity, or lack thereof, may be factored into the legal determination of competency. See Jessica Wilen Berg, et al., Constructing Competence: Formulating Standards of Legal Competence to Make Medical Decisions, 48 RUTGERS L. REV. 345, 346-47 n.14 (discussing the capacity-competence distinction). The terms are often used interchangeably in literature describing an individual's ability to make medical decisions.

19. The American Medical Association recognizes that individuals suffering from mental illness raise special considerations with regards to their competence. See Council on Ethical and Judicial Affairs, "Court-Initiated Medical Treatment in Criminal Cases," CEJA Report 4-A-98, (American Medical Association, 1998), available at www.ama-assn.org/ama1/pub/upload/mm/ code-medical-ethics/2065a.pdf [hereinafter "CEJA Report 4-A-98"]; see also infra Part II (explaining the complexities of applying the informed consent doctrine to decisions by individuals with mental illness).

20. See Berg, supra note 18 , at 351.

21. See id. (quoting Paul S. Appelbaum \& Thomas Grisso, Assessing Patients' Capacity to Consent to Treatment, 319 NEw ENG. J. MED. 1635, 1635-38 (1988)).

22. For a classification of different judicial determinations by the standards referenced above, see Berg, supra note 18, at 351 ("[T]hree or four compound standards [are] actually found in the cases and statutes: (i) choice and understanding, (ii) choice, understanding and appreciation, (iii) choice, understanding, appreciation, and reasoning, or (iv) choice, understanding and reasoning."). 


\section{The knowledge requirement correlates with the physician duty of disclosure}

Early formulations of informed consent described the physician's duty to disclose information as requisite for valid consent. ${ }^{23}$ Consent is invalid when given without adequate knowledge of the risks and benefits related to a particular intervention. ${ }^{24}$ Historically, the majority view considered the physician's perspective to judge whether the duty of disclosure was met. ${ }^{25}$ One application of the physician perspective view employs a customary practice standard to determine whether the disclosure of information by a physician was sufficient. Under this approach, disclosure is mandated unless it either (1) does not fall within the customary practice of physicians or (2) would contravene community or national medical standards. ${ }^{26}$ Several states adopt the customary practice standard, which often requires expert testimony to establish. ${ }^{27}$ Another somewhat more common approach is based on the physician's perspective and judges the adequacy of disclosure based on whether the physician acted in the

23. See generally Salgo v. Leland Stanford Jr. Univ. Bd. of Trs., 317 P.2d 170 (Cal. Ct. App. 1957) (marking one of the first formulations of the duty to disclose).

24. See Laurent B. Frantz, Modern Status of Views As to General Measure of Physician's Duty Inform Patients of Risks of Proposed Treatment, 88 A.L.R. 3d 1008 at $\S 2$ (1978).

25. See Robert D. Miller, Problems in Health Care Law 343 (9th ed. 2006) (noting that the current majority view is the reasonable patient standard).

26. See Frantz, supra note 24 , at $\S 3$.

27. See e.g., Hales v. Pittman, 576 P.2d 493, 499 at n. 4 (Ariz. 1978) ("The precise parameters of the required disclosure for any particular case is to be established by expert testimony in accordance with the applicable standard of medical care."); Eady v. Lansford, 92 S.W.3d 57, 60 (Ark. 2002) (" $[\mathrm{T}]$ he duty of a physician to disclose is measured by the customary disclosure practices of physicians in the community or a similar community."); Cobbs v. Grant, 502 P.2d 1,12 (Cal. 1972) (describing that under certain circumstances, "[a] disclosure may need not be made beyond that required within the medical community."); Bloskas v. Murray, 646 P.2d 907, 914 (Colo. 1982) ("The precise scope of the physician's duty of disclosure is determined on the basis of expert testimony demonstrating the extent of information given by reasonably careful physicians practicing the same specialty in the same or similar community."); Himes v. Gabriel, 2009 Del. Lexis 205, 206 (Del. Sup. Ct. 2009) ("Delaware law limits a physician's duty by requiring an injured party to prove that 'the health care provider did not supply information regarding such treatment, procedure or surgery to the extent customarily given to patients, or other persons authorized to given consent for patients by other licensed health care providers in the same or similar field of medicine as the defendant."); Whittington v. Mason, 905 So.2d 1261, 1266 (Miss. 2005) ("We hold that a plaintiff must produce expert testimony to establish material risks."); Curran v. Buser, 711 N.W.2d 562, 571 (Neb. 2006) ("[I]nformed consent means 'consent to a procedure based on information which would ordinarily be provided to the patient under like circumstances by health care providers engaged in a similar practice in the locality or in similar localities."'); McPherson v. Ellis, 287 S.E.2d 892, 897 (N.C. 1982) (citing state law which considers both the customary practice and the reasonable patient standards valid); Shadrick v. Coker, 963 S.W.2d 726, 732 (Tenn. 1998) ("Depending on the usual and customary advice given to patients to procure consent in similar situations, the health care provider must typically inform the patient of the diagnosis or nature of the patient's ailment."); Tashman v. Gibbs, 556 S.E.2d 772, 777 (Va. 2002) ("We have defined the standard of care in a medical malpractice action as that degree of skill and diligence exercised by a reasonably prudent practitioner in the same field of practice or specialty in Virginia."). 
manner that a reasonable physician under the circumstances might have acted. ${ }^{28}$ Both physician perspective views are consistent with the court's determination that some physician discretion may be appropriate - and indeed indicatedwhile still fulfilling the duty of disclosure. ${ }^{29}$

Concerns regarding potential abuse of discretion and threats to patient au-

28. Other states have applied the professional standard from the standpoint of the reasonably prudent practitioner. See, e.g., Fain v. Smith, 479 So.2d 1150, 1152 (Ala. 1985) ("In performing professional services for a patient, a physician's, surgeon's, or dentist's duty to the patient shall be to exercise such reasonable care, diligence and skill as physicians, surgeons, and dentists in the same general neighborhood, in the same general line of practice, ordinarily have and exercise in a like case."); Bloskas v. Murray, 646 P.2d 907, 914 (Colo. 1982) ("[A] claim in medical malpractice requires proof that the physician failed to exercise that degree of knowledge, skill and care used by other physicians practicing the same specialty."); Thomas v. Berrios, 348 So.2d 905, 908 (Fla. Dist. Ct. App. 1977) ("Expert testimony is required in informed consent cases to establish whether a reasonable medical practitioner in the community would make the pertinent disclosures under the same or similar circumstances."); Doreika v. Blotner, 666 S.E.2d 21, 24 (Ga. Ct. App. 2008) (requiring disclosure that would be provided by "reasonably prudent physicians" and that would be expected by "a reasonably prudent person"); Lisowski v. MacNeal Mem. Hosp. Ass'n. 885 N.E. 2d 1120, 1136 (Ill. App. Ct. 2008) (adopting a standard relying on what "the reasonable medical practitioner of the same school, or in similar circumstances," would disclose); Culbertson v. Mernitz, 602 N.E.2d 98, 104 (Ind. 1992) (affirming the use of the "standard of a reasonably prudent physician."); Leiker v. Gafford, 778 P.2d 823, 830 (Kan. 1989) (accepting that "the duty of the physician is limited to those disclosures which a reasonable medical practitioner would make under the same or similar circumstances."); Foster v. Oral Surgery Assocs., P.A. 940 A.2d 1102, 1106 (Me. 2008) ("[T] he scope of a physician's duty to disclose is measured by those communications a reasonable medical practitioner in that branch of medicine would make under the same or similar circumstances... ."); Harnish v. Children's Hosp. Med. Ctr., 439 N.E.2d 240, 243 (Mass. 1982) ("The information a physician reasonably should possess is that information possessed by the average qualified physician or, in the case of a specialty, by the average qualified physician practicing that specialty."); Lowder v. United States, 831 F. 2d 785, 786 (8th Cir. 1987) (supporting the patient centered approach to disclosure); Robinson v. Our Sisters of Charity, 963 P.2d 455, 455 (Mont. 1998) ("The duty of the physician to disclose, however, is limited to those disclosures which a reasonable medical practitioner would make under the same or similar circumstances."); Curran v. Buser, 711 N.W.2d 562, 571 (Neb. 2006) ("[I]nformed consent means "consent to a procedure based on information which would ordinarily be provided to the patient under like circumstances by health care providers engaged in a similar practice in the locality or in similar localities"'); Bronneke v. Rutherford, 89 P.3d 40, 43 (Nev. 2004) (supporting the professional medical standard for disclosure); Davis v. Nassau Ophthalmic Servs., P.C., 232 A.D.2d 358, 363 (N.Y. App. Div. 1996) (supporting the professional medical standard for disclosure); Miller v. Dacus 231 S.W.2d 903, 907 (Ark. 2007) ("The 'appropriate information' that must be disclosed depends on the usual and customary advice given to patients to procure consent in similar situations."); Tashman v. Gibbs, 556 S.E.2d 772, 777 (Va. 2002) ("We have defined the standard of care in a medical malpractice action as that degree of skill and diligence exercised by a reasonably prudent practitioner in the same field of practice or specialty in Virginia."). This standard applies also to the degree of information the physician is expected to know. See McGeshick v. Choucair, 9 F.3d 1229, 1233 n.1 (Wis. 1993) ("Physician's duty to inform [a] patient ... does not require disclosure of [ ] information beyond what reasonably well-qualified physician in similar medical classification would know....").

29. But see MILLER, supra note 25, at 343 ("The majority of states apply the reasonable patient standard under which the duty to disclose is determined by the patient's informational needs, not by professional practice."). See also generally Salgo v. Leland Stanford Jr. Univ. Bd. of Trs., 317 P.2d 170 (Cal. Ct. App. 1957). The concerns raised by the court in Salgo partially explain the movement towards the patient centered view. 
tonomy motivated a shift to the previous minority standard of materiality in some jurisdictions, which has now become the majority view. ${ }^{30}$ Rather than considering the physician perspective, the materiality standard instead considers what might be important to the decision maker. One formulation of this minority view requires the physician to disclose to the patient those risks that would be considered "material" to the patient in determining whether the proposed treatment should be undertaken, ${ }^{31}$ namely the knowledge a reasonable or

30. See Karp v. Cooley, 493 F.2d 408 (5th Cir. 1974). The court in that case recognized that a minority of jurisdictions utilized this materiality approach before affirming their own belief in the then majority physician perspective view. Id. The patient centered view has since become the majority view. See Miller, supra note 25, at 343 (describing the now majority patient centered view).

31. See Canterbury v. Spence, 464 F.2d 772, 786 (D.C. Cir. 1972) ("The patient's right of self-decision can be effectively exercised only if the patient possesses enough information to enable an intelligent choice."). The patient centered view is being upheld with greater frequency in more recent decisions. See Korman v. Mallin, 858 P.2d 1145, 1149 (Alaska 1993) ("[T] he scope of disclosure required ... must be measured by what a reasonable patient would need to know in order to make an informed and intelligent decision about the proposed treatment."); Eady v. Lansford, 92 S.W.3d 57, 60 (Ark. 2002) ("The minority view is that the duty of a physician to disclose is measured by the patient's need for information material to the patient's right to decide. ..."); Arato v. Avedon, 858 P.2d 598, 607 (Cal. 1993) ("[A] physician is under a legal duty to disclose to the patient all material information ... 'which the physician knows or should know would be regarded by a reasonable person in the patient's position."'); Levesque $v$. Bristol Hosp. 943 A.2d 430, 443 (Conn. 2008) ("[A] physician is obligated to provide the patient with that information which a reasonable patient would have found material for making a decision ...."); Miller-McGee v. Wash. Hosp. Ctr., 920 A.2d 430, 440 (D.C. 2006) ("The test for mandatory disclosure of information on treatment of the patient's condition is whether a reasonable person in what the physician knows or should know to be the patient's position would consider the information material to his decision."); Barcai v. Betwee, 50 P.3d 946, 960 (Haw. 2002) ("In order to determine whether a physician owes a duty to disclose a particular piece of information to the patient, this court ... has adopted the "patient oriented standard."); Kennis v. Mercy Hosp. Med. Ctr., 491 N.W.2d 161, 166 (Iowa 1992) (utilizing the standpoint of a reasonable patient to judge whether a given risk is a material risk); Jackson v. State, 938 So.2d 688, 690 (La. 2006) (indicating reliance on a standard that considers "whether a reasonable person in the patient's position would attach significance" to a risk); Wolinski v. Cohn, 713 N.W.2d 16, 21 (Mich. 2005) (implying reliance on the "reasonably prudent patient"); Plutshack v. Univ. of Minn. Hosp., 316 N.W.2d 1, 9 (Minn. 1982) (relying on the reasonable person standard for disclosure); Acuna v. Turkish, 930 A.2d 416, 425 (N.J. 2007) ("A physician has a legal duty to disclose to the patient all medical information that a reasonably prudent patient would find material . ..."); McPherson v. Ellis, 287 S.E.2d 892, 897 (N.C. 1982) (citing state law which considers both the customary practice and the reasonable patient standards valid); Long $v$. Jaszczak, 688 N.W.2d 173,180 (N.D. 2004) ("[U]ltimately, a 'trier of fact must determine whether a reasonable person in the plaintiff's position would attach significance to the specific risk."); Nickell v. Gonzalez, 477 N.E.2d 1145, 1148 (Ohio 1985) ("“T] he reasonable patient standard is utilized."); Scott v. Bradford, 606 P.2d 554, 558 (Okla. 1979) (indicating that the standard for disclosure is not the professional standard but instead "based on the patient's need to know"); Holland v. Sisters of St. Joseph of Peace, 522 P.2d 208, 211 (Or. 1974) (relying on the significance that a reasonable person would attach to a given risk); Morgan v. MacPhail, 704 A.2d 617, 621 ( $\mathrm{Pa}$. 1997) ("[A] doctor must disclose risks that a reasonable man would consider material ....”); Beauvais v. Notre Dame Hosp., 387 A.2d 689, 692 (R.I. 1978) (indicating that the jury should rely on the materiality of a given risk to a reasonable person"); Savold v. Johnson, 443 N.W.2d 656, 658 (S.D. 1998) ("A risk is defined as material when a reasonable person, in what the physician knows or should know to be the patient's position, would be likely to attach significance to ...."); Shadrick v. Coker, 963 S.W.2d 726, 733 (Tenn. 1998) (requiring 
prudent patient would require in order to make an informed decision. ${ }^{32}$ The reasonableness element incorporated in this position asks the physician to consider the relative weight an ordinary person might give to various risks and benefits of a particular decision. Under this view, a specific risk or benefit, particularly when externally imposed, may shift from being important or material in the decision making process to becoming frankly coercive, and requires special attention in the context of mental illness. ${ }^{33}$

\section{The requirement that informed decisions be voluntary provides the last protection for patients}

The final requirement for judging whether a decision to forego or undertake a particular medical intervention was made with informed consent is that the decision was made voluntarily. "A decision is considered involuntary when some element is involved that prevents an individual from acting freely. . .. 'Coercion is established by demonstrating that duress induced individuals to give their consent where they would not have otherwise done so.",35 The liberal view of this voluntariness requirement for consent stipulates that "[ $t]$ he patient's decision should not be coerced or pressured by anyone,"36 while a more stringent view does not require all coercive circumstances to render a decision necessarily involuntary. ${ }^{37}$ The impact of coercion in rendering consent involuntary might be explained by considering whether the coercive influence was internal to the individual's own value system or whether it was imposed externally and in such a way that negates autonomy. The bioethics literature offers an alternative understanding of coercion which considers certain control-

disclosure of what a reasonable patient would care to know); Stewart-Graves v. Vaughn, 170 P.3d 1151, 1155 (Wash. 2007) (relying on state law requiring disclosure of facts felt important to a "reasonably prudent person"); Hannemann v. Boyson, 698 N.W.2d 714, 725 (Wisc. 2005) (rejecting a standard based on the "customs of the profession").

32. See Chamberlain v. Giampapa, 210 F. 3d 154, 161-62 (3rd Cir. 2000) (describing the "reasonably prudent patient" standard); see also generally Howard v. Univ. of Med. \& Dentistry of N.J., 800 A.2d 73 (2002) (upholding the "prudent patient" or "materiality of risk" standard).

33. See infra notes 38-39 and accompanying text (arguing that externally imposed autonomy-negating factors are more likely coercive). The currently applied legal standard relies on the rational actor model to allow exploitation of external influences to occur, by heralding that a reasonable person must be told everything that could and should be potentially material to a decision regarding an intervention. When coupled with the view held by some that not all coercive circumstances make a decision involuntary, the patient materiality standard may actually be dangerous for patients with mental illness where vulnerability to external influences can be exploited. See infra note 37 and Part I.B.3 for a discussion of the voluntary requirement and the view that coercion does not always lead to a finding of involuntariness.

34. See CEJA Report 4-A-98, supra note 19, at 3 ("Informed consent is by definition voluntary.").

35. Id. (quoting KA Vanderzyl, Castration As an Alternative to Incarceration: An Impotent Approach to the Punishment of Sex Offenders, 15 N. ILL. L. REV. 107 (1994)).

36. O'Sullivan \& Borcherding, supra note 6, at 72 (emphasis added). In the most liberal formulation of the voluntariness requirement, then, all coercion or pressure by anyone (assumedly focusing on primarily external influences) invalidates consent.

37. See CEJA Report 4-A-98, supra note 19, at 3 ("It is possible to give voluntary consent under certain coercive circumstances."). 
ling external influences to be autonomy-negating and therefore coercive. ${ }^{38}$ This view recognizes that factors external to the decision at hand which force a particular "choice" are coercive. ${ }^{39}$ The risk of coercion is heightened in individuals with mental illness because of the particular influence of external factors in their decisions regarding treatment.

\section{MENTAL ILLNESS ${ }^{40}$ RAises SPECIAL CONSIDERATIONS WHEN CONTEMPLATING INFORMED CONSENT}

It can be particularly difficult-if not impossible- to obtain consent from individuals with mental illness without applying particular safeguards because of the impact that mental illness can have on one's capacity to understand and to weigh factors in a decision, and the frequent desire of individuals with mental illness to be accepted in a moral community.

\section{A. Many Individuals with Mental Illness may not have the Requisite Capacity to Consent}

A finding of competence is generally based on the interplay of several factors, including: rationality, understanding, the ability to weigh consequences, and the ability to communicate. ${ }^{41}$ Data suggests that individuals with mental illness, however, are less likely to be competent in any one area. "[P]atients hospitalized with schizophrenia or depression more often show[] deficits in

38. See M. Gregg Bloche, Beyond Autonomy: Coercion and Morality in Clinical Relationships, 6 HEALTH MATRIX 229, 247 (1996) (explaining a three-part test for an autonomynegating external influence). The article also notes that a finding of coercion is not always per se immoral. See id. at 240 ("[T] he conclusion that an influence method constitutes coercion does not imply that the method is morally wrong."). Part III of this Article argues that coercion in the context described in this paper, however, is immoral because it negates the principle of autonomy that is central to the moral theories discussed.

39. See id. at 244 (arguing that conditioning medical care for HIV-positive women on their decision towards reproductive abstinence is coercive).

40. The argument made here applies only to mental illness and not to mental retardation. This distinction is made for several reasons. First, mental illness and mental retardation raise similar but not identical concerns with regards to informed consent. Second, the discussion regarding informed consent in this Article precedes a consideration of what factors, including accountability, might be important in assessing the moral agency of mentally ill individuals. The tension between the expectation of accountability and the principle of autonomy inherent to the doctrine of informed consent is more pronounced in individuals with mental illness than in those with mental retardation. For ease of characterization, those disorders listed in the Diagnostic and Statistical Manual IV, for example, depression, schizophrenia, and bipolar disorder, form the basis of this Article's treatment of mental illness. Furthermore, the discussion assumes that mental illnesses exist as diagnosable and potentially treatable conditions. Thus, considerations might attribute to this group of individuals that may not be as strongly supported in consent discussions for non-mentally ill individuals. For a view that mental illness is a fiction, see Thomas Szasz, Mental Disorders are not Diseases, USA TODAY (2000), available at http://www.szasz.com/usatoday.html.

41. See supra notes 18-22 and accompanying text (describing the competence element of informed consent). 
their decision making than hospitalized medically ill patients and non-patient comparison groups." 42 Furthermore, individuals with schizophrenia demonstrate a greater deficit than individuals with depression. ${ }^{43}$ Those "patients who manifest[] greater severity of thought disturbances, also tend[] to manifest deficits in understanding and reasoning." 44 Additionally, "although patients with schizophrenia show[] the greatest impairments, the majority of these patients perform[] in the "unimpaired" range on each measure" 45 These individuals therefore will be judged competent by courts. ${ }^{46}$

On a normative level, the choice between standards [employed to judge competency] involves balancing the extent to which a failure to demonstrate the ability measured by a component indicates impaired autonomy in decisionmaking against whether such a failure is a sufficient basis for limiting a patient's decisionmaking authority. Although seriously impaired people should be protected, the right to make decisions for oneself should not be burdened more than is absolutely necessary. In consequentialist terms the issue is whether the harm of incorrectly labeling autonomous agents as incompetent is outweighed by the harm of incorrectly labeling nonautonomous agents as competent. The former is a harm to the patient's autonomy, or right of self-determination. The latter is only significant to the extent that the patient's well-being is at risk; no harm results from allowing an incompetent patient to make a decision of minimal effect or one that is in keeping with his or her objective best interests. Only competent patients, however, are free to make decisions that are not in their best interests. ${ }^{47}$

42. Berg, supra note 18 , at 372 .

43. Id.

44. Id. at 374 .

45. Id. at 373.

46. Id. Courts may choose to find a larger percentage of persons competent than would be judged competent by the statistical measures used in studies examining competence. See id. at n.92 ("There are problems in using statistical cut-off points to set competence criteria. ...").

47. Id. at 377. While this is a nuanced point, the choice of terms used here is incorrect. One could argue that all individuals are always autonomous. A judgment of competency determines whether at a particular point in time an individual is capable of exercising his autonomy in accord with her preferences. Regardless of that determination, this individual does not become nonautonomous. This view defines autonomy based both on the individual and the choices she makes. See Tom L. Beauchamp \& James F. ChILdREss, Principles OF BIOMEdical ETHICs 38 (5th ed.) (2001) (discussing the distinction between the autonomous person and autonomous choice). 
In the case of mental illness where the benefits of particular interventions are questionable and the risks arguably significant, ${ }^{48}$ the risk and detriment of having an incompetent person judged competent is more real. Although no harm may result from allowing an incompetent patient to decide on issues with "minimal effect," the decisions regarding interventions for mental illness are rarely with "minimal effect". ${ }^{49}$ In practice, however, we act as if they were. Under the premise of respecting autonomy, courts generally do not question competency when the mentally ill individual acts in the way that others recommend or expect. ${ }^{50}$ Instead, judgments of competence for mentally ill persons are mostly triggered when the individual chooses not to act in accordance with the recommended treatment. ${ }^{51}$ For many individuals with mental illness, however, the rational choice would seem to be not to medicate given the potential risks of many of the available medical interventions for mental illness. ${ }^{52}$ Still, the deci-

48. See infra Part II.B for a discussion of the risks and perceived benefits of interventions for mental illness.

49. See Berg, supra note 18, at 377 (implying that competence is of less importance with issues of minimal effect).

50. The purpose of this argument is not to say that mentally ill individuals can never give informed consent or act autonomously. Rather it is to say, that judging informed consent where mental illness is concerned should receive more scrutiny than it does and perhaps that it should be more difficult than it is to presume consent was given and adequately informed. Because obtaining invalid consent in this population may be more common than is credited, any threats to informed consent should be minimized, so that the practice does not become even less meaningful than it has already. See infra Part III for a discussion of ethical considerations in coercively obtained consent (suggesting that preserving the moral agency of mentally ill patients in part entails respecting decisions regarding bodily integrity that may conflict with societal goals and values).

51. See Wenona Whitfield, Capacity, Competency and Courts: The Illinois Experience, 14 WASH. U. J.L. PoL'Y 385, 285 (2004) ("When mental health patients refuse to accept voluntary administration of psychotropic medicine, Illinois is one of several states that provides for a judicial hearing to determine whether the patient's wishes should be overruled."). Psychotropic medications include those medications that are "capable of affecting the mind, emotions, and behavior; denoting drugs used in the treatment of mental illnesses." STEDMAN's CONCISE MEDICAL DictionaRY FOR THE HEALTH PROFESSIONS 817 (4th ed. 2001) (defining psychotropic). The decision to refuse medical treatment most commonly invokes a discussion of competency because attempts to involuntarily administer treatment to a competent patient have failed. See generally Rogers v. Comm'r of Dep't of Mental Health, 458 N.E.2d 308, 314, 321-22 (Mass. 1983); Opinion of the Justices, 465 A.2d 484, 489 (N.H. 1983). A determination that a patient is incompetent will allow an institution to forcibly medicate this patient on a theory of perceived patient interests and the patient's own inability to choose the best option.

52. See infra Part II.B for a discussion of the considerations which should be disclosed and the impact that such disclosures might have on the decision to refuse medication. For an in depth discussion of the right to refuse drugs, which is beyond the scope of this discussion, see generally William M. Brooks, Reevaluating Substantive Due Process as a Source of Protection for Psychiatric Patients to Refuse Drugs, 31 IND. L. REV. 937, 991 (1998) ("No one can seriously dispute that forcing a person diagnosed as mentally ill to accept medication shapes a substantial aspect of the person's life, which abridges a patient's right to bodily autonomy."). The discussion of medication refusal is relevant for the purposes of demonstrating motivations for competency assessments when parties use these assessments to argue against an individual's right to refuse treatment. But, "[t] $]$ he logical corollary of the doctrine of informed consent is that the patient generally possesses the right not to consent, that is, to refuse treatment." Cruzan v. Dir., Mo. Dep't of Health, 497 U.S. 261, 270 (1990). The "right to refuse" cases are also useful 
sion to medicate, which may be viewed as the irrational decision, almost never prompts a competency assessment. Instead, the competency component of informed consent only appears to come into question when the mentally ill individual makes the arguably rational choice not to medicate. This reality makes competence a particularly important component of consent for individuals with mental illness because it can be easily manipulated to find competence when the individual agrees to treatment desired by others and incompetence when such treatment is refused. In many ways, competence is the most important element of informed consent for individuals with mental illness because, when the individual agrees to treatment, the elements of disclosure and voluntariness are not questioned. When the individual refuses treatment, there is no duty to disclose because what might be important to a reasonable person would be irrelevant to the incompetent individual and treatment under these circumstances is by definition involuntary. Thus, these factors seem to receive less consideration in the legal interpretation of informed consent for individuals with mental illness. Nevertheless, they provide other points of vulnerability in applying the doctrine of informed consent to those with mental illness and merit consideration.

\section{B. Knowing How Far the Duty to Disclose Extends Becomes Especially Difficult When Dealing with Mental Illness}

The requisite knowledge to judge whether a particular individual's consent is informed correlates with the physician's duty to disclose information in obtaining the consent. This duty can be judged either from the physician's perspective or the patient's perspective. The physician perspective requires physicians to disclose what would be traditionally disclosed by practitioners in similar circumstances, while the patient perspective requires the physician to disclose what a reasonable patient may find material in making a decision under the same circumstances. ${ }^{53}$ Both formulations contemplate the impossibility of disclosing every possible outcome in any given intervention and both recognize that the physician's duty extends only as far as his own knowledge does. Regardless of the perspective from which the disclosure duty is framed, the consequences of these premises are particularly important when considering what to disclose to mentally ill individuals for three reasons.

in illuminating the important liberty and privacy issues that create part of the foundation for the informed consent doctrine. See generally Brandeis and Warren, supra note 10.

53. See supra notes 23-33 and accompanying text (discussing in general the physician's duty to disclose in the process of obtaining informed consent). 


\section{Treatments for mental illness are incompletely developed and carry with them the risk of significant adverse effects ${ }^{54}$}

The approach to treating the patient with mental illness is, as a whole, not a precise a science. While there is a substantial degree of variability that accompanies the treatment of any condition with medication, in the treatment of mental illness, "trial-and-error" is more the norm than the exception. ${ }^{55} \mathrm{Know}$ ledge regarding treatment for mental conditions is incomplete largely because knowledge about mental illness is itself incomplete. ${ }^{56}$ Therefore, it will be difficult, if not impossible, for the physician to assert that treatment for mental illness will be beneficial in any given case because she simply cannot know this a priori.$^{57}$ Antipyschotic drugs do not promise to cure mental illness; at best, they offer a reduction in some, but not all debilitating symptoms associated with mental illness. ${ }^{58}$ In a substantial number of patients, medication will not provide any benefit, and rarely will medication provide complete relief. ${ }^{59}$ Because of the lack of effective interventions in treating mental illness, the physician faces special problems in meeting her duty of disclosure in a meaningful way. The physician will be able technically to meet her duty of disclosure because the duty only expects her to reveal what she knows (and logically cannot expect more); however, while legally appropriate, this still may leave the patient to decide without information that is material to an adequately weighed decision.

The high probability and severity of side effects associated with many

54. Undoubtedly, for some individuals, pharmacologic intervention can be and is the most effective way for them to deal with their mental illness. To the extent that such individuals have given legally valid informed consent, after a consideration of the particular vulnerabilities of the informed consent doctrine in the context of mental illness, these situations are not problematic. This Article instead focuses on the concern that if moral agency is conditioned on one's compliance with treatment, the majority of individuals with mental illness will not be provided the opportunity to give valid non-coerced consent to their treatment because of the complexities of the consent doctrine in mental illness. See infra Part III.

55. See Brooks, supra note 52, at 946 ("Physicians must prescribe antipsychotic drugs on a trial and error basis as there is no accurate method of determining how a patient will respond to a particular drug.").

56. See generally Mental Health, Meaning of Mental Health, in ENCYCLOPEDIA OF BIOETHICs 1757-65 (Stephen G. Post ed., 3d ed. 2004) (exploring difficulties in defining mental illness); Mental Illness, in ENCYCLOPEDIA OF BIOETHICS 1789-1815 (Stephen G. Post ed., 3d ed., 2004) (suggesting that cultural and temporal effects also impact understanding of mental illness); see also Ake v. Oklahoma, 470 U.S. 68, 81 (pointing to difficulties with psychiatric diagnoses); Addington v. Texas, 441 U.S. 418, 429 (1979) (same).

57. There are a number of other conditions in which the physician is uncertain about the expected benefit of a particular intervention and this alone does not invalidate consent. In those cases as well, there is a higher burden of demonstrating that the individual truly understood the risks she was taking relative to the uncertain benefit and made a reasoned decision based on this assessment. In the context of mental illness, this problem is of special concern because the entire informed consent process is more vulnerable and the known risks of most psychotropic medications are substantial.

58. See Brooks, supra note 52, at $945-46$ (discussing the role and promise of psychotropic medications).

59. Id. at 946 (discussing the role and promise of psychotropic medications). 
pharmacologic interventions for mental illness complicates the lack of complete information regarding the nature of mental illness. " "[I]t is difficult to imagine intrusions on the body that are more significant than the administration of antipsychotic and other psychotropic medication. Antipsychotic medication is, by definition, mind-altering in nature, and presents a risk of debilitating side effects that may be permanent." are common to many pharmacologic interventions, psychotropic medications may also result in potentially long-standing, serious, and even life-threatening side effects. ${ }^{62}$ Some of the most disturbing symptoms resulting from use of psychotropic medications, particularly antipsychotic agents, are extrapyramidal symptoms, which result from a disturbance of motor function in the brain. ${ }^{63}$ The extrapyramidal symptoms can be divided into hyopkinetic or decreased movement disorders and hyperkinetic or increased movement disorders. ${ }^{64}$

The hypokinetic disorders associated with psychotropic medications include akinesia and Parkinsonism or decreased speed of movement. ${ }^{65}$ Akinesia produces a clinical picture in which individuals have difficulty initiating movement. ${ }^{66}$ The presentation is "characterized by unspontaneous speech, apa-

60. See Washington v. Harper, 494 U.S. 210, 229 (1990) (acknowledging the possibility of such dangerous side effects). This Article spends much time discussing the nature and consequence of the side effects of psychotropic medications precisely because knowledge of these side effects, coupled with low expectations that a given intervention will be effective, logically supports the notion that a purely rational actor, when considering the pharmacologic intervention in isolation, would likely opt not to medicate. It may be argued that in other conditions, patients choose to attempt interventions which may be considered to have a low probability of success or even judged futile. Indeed, in an attempt to relieve certain terminal conditions, particularly in the field of oncology, some people may choose such interventions even when significant side effects are possible. These cases demonstrate that it is not necessarily irrational for a person to select an option that has low probability of success and great possibility of significant harm, but these circumstances can be distinguished from the situation of mentally ill patients on at least two grounds: (1) in general, such choices are made when the individual is facing a life terminating condition if some intervention is not selected, and (2) any coercive pressure this potential factor plays in their decision is inherent to the condition itself and not external factors. See supra Part II.C (discussing how external factors exploiting weaknesses of mentally ill persons may be used to coerce compliance with treatment regimens).

61. The courts have agreed with this viewpoint. See Harper, 494 U.S. at 229 (recognizing the danger of side effects); see also Brooks, supra note 52, at 991; ELYN R. SAKS, REFUSING CARE: ForCED TREATMENT AND THE RIGHTS OF THE MENTALLY ILL (2002) (discussing the "mind altering" and "thought suppressing" nature of drugs); George P. Smith, II, "Just Say No!": The Right to Refuse Psychotropic Medication in Long-Term Care Facilities, 13 ANNALS HEALTH L. 1,4 (2004) (addressing the side effects of psychotropic medications).

62. Despite the lack of certainty surrounding the benefit of psychotropic medications, they are widely accepted in the psychiatric community. See Harper, 494 U.S. at 226 n.9.

63. See Christopher G. GoETZ, TEXTBOOK OF ClniCAl NeURology 289 (2003) [hereinafter TEXTBOOK OF NEUROLOGY] (describing extrapyramidal symptoms as a "class of motor disturbances"). nesia.").

64. See id. ("Movement disorders are clinically characterized by hypokinesia or hyperki-

65. Id.

66. Id. (characterizing akinesia as absence of movement). 
thy and difficulty initiating activities. ${ }^{, 67}$ Parkinsonism can involve akinesia in addition to other features characteristic of Parkinson's disease, "mask-like fac[ies], drooling, muscle stiffness, and rigidity," ${ }^{, 68}$ along with a resting tremor and possibly inadequate responses to changes in posture. ${ }^{69}$

The hyperkinetic disorders associated with psychotropic medications include akasthesia, dystonia, and tardive dyskenesia. ${ }^{70}$ Akasthesia is a motor disorder characterized by "uncontrollable physical restlessness, agitation, pacing, anxiety and panic," potentially joined by "a constant tapping of feet, alteration of posture ... and an inability to feel comfortable in any position." ${ }^{, 71}$ Because psychomotor agitation is also a symptom of many psychiatric diagnoses, ${ }^{72}$ this presentation may prompt administration of even higher doses of the offending agent, under a false belief that the underlying psychiatric disorder is not adequately managed. ${ }^{73}$ Dystonia is a spastic muscle reaction. The most common locations for dystonic reactions secondary to psychotropic medications include the eyes, neck, face, and arms. ${ }^{74}$ Dystonic reactions will generally subside when the offending medication is discontinued. ${ }^{75}$ The most troubling motor reaction to psychotropic medication is tardive dyskinesia. This disorder is associated with long term psychotropic medication usage and involves involuntary movements of the muscles of the face, arm, leg, or trunk. ${ }^{76}$

67. See Theodore Van Putten \& Stephen R. Marder, Behavioral Toxicity of Antipsychotic Drugs, 48 J. CliniCAL PsyChIATRY 13, 15 (Supp. 1987) (describing akinesia).

68. Robert Plotkin, Limiting the Therapeutic Orgy: Mental Patients' Right to Refuse Treatment, 72 Nw U.L. REV. 461, 475 (1978) (explaining the features of Parkinsonism).

69. TEXTBOOK OF NEUROLOGY, supra note 63 , at 280 . Normally, when a person changes their posture, reflexive mechanisms in the body will cause certain muscle contractions to occur in order to maintain a certain blood pressure. Id. Loss of initiating movement mechanisms in patients with features of Parkinsonism can result in loss of this postural reflex. Id. Parkinsonism may occur in up to ninety percent of patients on psychotropic medications. Brooks, supra note 52, at 948 (quoting Dennis E. Cichon, The Right to "Just Say No": A History and Analysis of the Right to Refuse Antipsychotic Drugs, 53 La. L. Rev. 283, 300 (1992)).

70. TEXTBOOK OF NEUROLOGY, supra note 63, at 280.

71. See Brooks, supra note 52, at 947.

72. See generally AMERICAN Psychiatric Association, DiAGNOSTIC AND STATISTICAL MANUAL IV (4th ed. Text Revision 2000) [hereinafter DSM-IV-TR]. Psychomotor agitation may be part multiple diagnoses, including psychotic disorder not otherwise specified, depression with psychotic features, schizophrenia, and bipolar disorder. Id.

73. See Peter J. Weiden, et. al., Clinical Nonrecognition of Neuroleptic-Induced Movement Disorders: A Cautionary Study, 144 AM. J. PsYCHIATRY 1148, 1151 (1987) (discussing this trend).

74. Brooks, supra note 52, at 948.

75. Id. It should be noted that this is still a disabling reaction, and may disappear if the medication is discontinued. This potential relief is irrelevant, however, if an individual experiences the reaction with each medication attempt and there is an expectation that they will remain on their medication if it controls the symptoms of their underlying psychiatric disorder regardless of its secondary effects.

76. See Dilip V. Jeste et al., The Biology and Experimental Treatment of Tardive Dyskinesia and Other Movement Disorder, in 8 AMERICAN HANDBOOK OF PSYCHIATRY 536, 537 (Berger \& Brodie, eds., 2d ed. 1986) (describing this troubling side effect). Upon discontinuation of psychotropic medications, symptoms of tardive dyskinesia may initially worsen. TEXTBOOK OF NEUROLOGY, supra note 63 , at 1228 . They may potentially be lessened or re- 
A non-motor related but potentially life-threatening reaction to initiating or increasing psychotropic medications is neuroleptic malignant syndrome. ${ }^{77}$ An incompletely understood mechanism mediates this multi-organ syndrome which causes increased temperature, stiffening of muscles, inadequate functioning of one part of the nervous system important in maintaining life-sustaining bodily activities, and changes in level of mental status. ${ }^{78}$

The unique challenges that diagnosis and treatment of mental illnesses create for the duty to disclose result directly from both the disagreement about the criteria for diagnosis of these conditions and also the varying reports and beliefs regarding the success of various interventions. When examined in the context of the knowledge requirement of informed consent, it is unclear how this information can possibly be conveyed to patients in a useful way to meet the disclosure component of consent. Because of the lack of certainty regarding the diagnosis of mental illness and the unpredictability of response, it seems on a practical level that interventions in mental illness are experimental in almost every specific instance, even if there is a general consensus that pharmacologic intervention can be effective in treating mental illness. ${ }^{79}$

\section{The physician perspective standard provides a great deal of deference in disclosure to patients}

Criticisms of the physician's perspective approach to the duty of disclosure are particularly relevant to the community of individuals with mental illness. One of the strongest criticisms of the approach is that it will permit a physician to refrain from disclosing information that might be relevant to a particular patient if it is not customary to do so. ${ }^{80}$ With the numerous consequences that can result from treatment with psychotropic medication, it would likely be impossible for any physician to obtain consent for treatment if all po-

lieved by changing to a newer antipsychotic medication with a lower incidence of such effects or by waiting several years after discontinuation of therapy. Id. Unfortunately, however, one of the more promising agents for patients who suffer from tardive dyskinesia, clozapine, acts to lower the threshold for seizures in individual patients. Id. at 1286 . This may either aggravate existing epilepsy or induce epilepsy de novo. In either case, it replaces one negative effect with another.

77. See TEXTBOOK OF NEUROLOGY, supra note 63 , at 1227 ; see also Brooks, supra note 52 , at 950 .

78. See TEXTBOOK OF NEUROLOGY, supra note 63, at 1227 (explaining the features of the syndrome).

79. The ethical principles which inform and argue against medical experimentation in other contexts, especially with vulnerable populations such as children, may help to inform this discussion as well. See Holly Fernandez Lynch, Give Them What They Want? The Permissibility of Pediatric Placebo-Controlled Trials Requested Under the Best Pharmaceuticals for Children Act, 16 ANNALS HEALTH L. 79, 80 (2007) ("[P]ediatric subjects . . . are developmentally and legally incapable of providing consent on their own, and thus require more protection from abuse and exploitation in research."). While competent individuals with mental illness still ought to be able to consent on their own, they warrant similar protection from abuse and exploitation.

80. See supra notes $23-33$ and accompanying text (discussing the physician and patient perspective approaches to the duty of disclosure). 
tential effects were disclosed. It may therefore become customary to disclose only those most serious or life threatening consequences, when other effects may be perceived as important by patients. A shift to the patient-centered perspective offers only the illusion of a better information exchange. ${ }^{81}$

\section{The "patient centered" materiality standard inadequately accounts for variability in symptoms of mental illness}

Focusing on the patient perspective, courts have accepted a materiality standard against which the adequacy of physician disclosure is judged. ${ }^{82}$ Information that may be deemed relevant by a "reasonably prudent patient" under similar circumstances must be disclosed under this standard. ${ }^{83}$ Seemingly, this should afford improved information exchange between physicians and individuals with mental illness. "Reasonable" behavior, however, may differ not only for different mental illnesses and different proposed treatments but for also for different individuals with the same illness. This is a feature not only of the unavoidable consequence that different individuals will respond differently to the same treatment but also of the known fact that individuals who can pass a competency evaluation - and who will then be judged by the materiality standard of the reasonably prudent patient with " $X$ " disease - may be impaired to different degrees. ${ }^{84}$ Because physician judgments regarding the severity of mental illness are fairly rudimentary, absent useful instruments to objectively measure disease severity for mental conditions, patients with mental illness are less likely to receive the information they need relative to their level of impairment in order to make an informed decision. ${ }^{85}$ This discrepancy points to another vulnerability in the consent process for treatment of mental illness.

81. See MILLER, supra note 25 (describing the patient centered view). In addition to the considerations below, a fundamental difficulty in the patient-centered perspective, is that it only requires disclosure of material risks; there is no restriction on how this information will be presented to the patient. In general, the effective presentation of risks is a necessary component of consent. The physician must be able to judge when a patient needs more or less information in order to make an informed decision. Any attempts to script the communication which occurs between a physician and patient will likely be detrimental to the practice of medicine as a whole because they do not appreciate the benefit of the physician-patient relationship in helping the physician to determine what information needs to be disclosed. See Arthur Caplan, Abortion Politics Twist Facts in Fetal Pain Laws: Proposed Bills that Address Fetal Suffering Go Beyond Medical Evidence. MS-NBC Commentary (Nov. 28, 2005), available at http://www. msnbc.msn.com/id/10238840/. Still, the presentation of risks and benefits is important. For example, most people will respond more strongly to a potential risk presented as a loss than a potential benefit presented as a gain. In the case of mental illness, then, when the risks are so significant and the benefits unlikely to be significant, the emphasis the physician puts on even material disclosures will undoubtedly influence the patient more so than in other contexts.

82. See Chamberlain v. Giampapa, 210 F. 3d 154 (3rd Cir. 2000) (applying the patient materiality standard).

83. See id. at 161-62 (describing the "reasonably prudent patient" standard).

84. See supra Part II.A (underscoring difficulties with competency assessments unique to mental illness).

85. Arguably, all persons with medical conditions may be afflicted to varying severity and 


\section{Individuals with Mental Illness are Particularly Vulnerable to Coercion that may Make Consent Involuntary}

Perhaps the greatest vulnerability, which can be exploited in the consent process, is the requirement that consent be voluntary. While viewpoints vary regarding whether pressured consent can nevertheless be voluntary, legally effective consent must, by definition, be voluntary. ${ }^{86}$ Voluntary consent is "consent that is given freely and that has not been coerced." general form means to compel a particular action by the threat of physical force. ${ }^{88}$ Taken together then, any consent obtained by an individual threatened with physical force would be invalid. Mentally ill individuals often face a choice among several physical threats. Absent consent to physical administration of pharmacologic agents - with all of their attendant risks and uncertain benefits - the mentally individual may be threatened with physical restraints for "behavioral control" or incarceration for acts committed that are the believed result of his mental condition. ${ }^{89}$ Such choices, undoubtedly weigh heavily into the individual's decision to begin often-lifelong relationships with pharmacologic agents that can wreak havoc on body and mind. ${ }^{90}$

therefore will require varying degrees of information to make a decision regarding their treatment.

86. See BLACK's LAW DictionaRY 255-56 (8th ed. 2005) (defining consent).

87. Id.

88. See BlaCK's LAW DictionaRy 215 (8th ed. 2005) (defining coercion).

89. Agreement to pharmacologic treatment may result from coercive conditions such as incarceration, institutional release conditioned on compliance, and institutional privileges granted based on compliance. See generally Slodov, supra note 1 (suggesting one coercive mechanism by which compliance can be assured). To the extent that these arrangements encourage accountability for their condition, such "choices" may actually be thought to present the mentally ill individual the opportunity to demonstrate her moral agency by making the "correct decision" to medicate and avoid future harm. Such an expectation, however, actually undermines the doctrine of informed consent, thereby challenging the very autonomy that is requisite to any theory of moral agency. See infra Part III (concluding that coercively obtained consent is also unethical because it undermines autonomy).

90. The view espoused by the American Medical Association comports with the idea that such "preferences" appropriately weigh into these decisions. The Council writes that "the decision to undergo a medical procedure so as to avoid a lengthy incarceration seems neither irrational nor involuntary." CEJA Report 4-A-98, supra note 19, at 3 . Under the legal understanding of consent and coercion, such a decision may indeed be rational but is arguably not voluntary. The viewpoint that coercive consent obtained by using the threat of losing one's freedom (or even moral worth) could be voluntary is somewhat absurd if considered in another context. It would be easy to imagine a law that judges fetuses to be humans. Coupled with laws that make killing all humans a crime, such a legal framework would make abortion a crime. According to viewpoints that coercive consent can nevertheless be voluntary consent, this does not invalidate an individual woman's choice of whether to obtain an abortion. She could choose to protect her bodily integrity against the effects of pregnancy. The cost, however, might be her freedom. But views that permit coercive consent could not call this consent any less voluntary than the mentally ill individual whose consent is obtained under threat of detention, restraint, or refusal to allow membership in the moral community absent an agreement to control his illness through medication. Both could rank freedom high in their consideration of preferences, and then give consent to something they would otherwise not want--the woman to carrying a child, the mentally ill person to medication with uncertain probability of success and certain probability of unwanted side effects. Conditioning access to health care on reproductive abstinence is 
The moral community has the potential to coerce seemingly involuntary consent without the threat of physical force. Moral coercion, defined as undue influence, can hold invaluable weight for the mentally ill community. ${ }^{91}$ Among descriptions of mental illness, a recurrent theme emerges - the mentally ill are many times tortured by their desire to make the morally correct choice, despite their performance of the morally incorrect one. "These discrepancies between what one is, what one is brought up to believe is the right way of behaving toward others, and what actually happens during these awful black manias ... are absolute and disturbing beyond description." her cooperation with a pharmacologic regimen creates an impermissible undue influence on the capacity to choose, because it ties the decision to medicate to an external goal which drives the decision. ${ }^{94}$ Without a real choice, the decision to submit to pharmacologic therapy is involuntary, and informed consent cannot be deemed legally effective. ${ }^{95}$

similarly coercive. See generally Bloche, supra note 38 (making the argument that this type of condition would also be immoral).

91. See Black's Law Dictionary 215 \& 1276 (8th ed. 2005); see also O'Sullivan \& Borcherding, supra note 6, at 72 ("Many people with mental retardation and mental illness have a great desire to please those in authority.").

92. See generally KAY JAMISON, AN UNQUIET MIND (1995); ANDY BEHRMAN, ELECTROBOY (2002).

93. JAMISON, supra note 92 , at 120-23. The failure to make the right choice is even more disturbing when the individual realizes that to make the choices he makes, "[he knows] that [he] is sabotaging [himself]". BEHRMAN, supra note 92, at 20-23.

94. See Blouche, supra note 38, at 247 (explaining that an autonomy-negating external influence is coercive). Below, this Article considers whether it may be permissible to coerce such cooperation as it may be deemed necessary pending a more appropriate way for society to respond to the needs and results of mental illness; however, to do so under the false premise that this individual has voluntarily consented to something when he was left with no real choice to do otherwise diminishes the value of the informed consent doctrine.

95. The foregoing discussion highlights the difficulty in determining whether informed consent was given for pharmacologic treatment in mental illness. While the problems may appear to invalidate the doctrine of consent completely as applied to mental illness, this is not a necessary result or the intent of the discussion. There will indeed be some patients who are competent to make decisions given the appropriate amount of education by a health care provider such that information important for this individual is disclosed. Furthermore, not all consents to treatment with pharmacologic therapy will be affected by moral coercion or physical coercion that can also serve to invalidate consent. These considerations should be contemplated whenever consent is obtained for treatment of mental illness; if they have not been contemplated, truly informed consent has not been secured. Even without consent, it may be ethically and legally justifiable to expect mentally ill individuals to submit to treatment when the criteria for involuntary treatment have been met. See supra note 6. 


\section{WHÉRE INFORMED CONSENT IS LEGALLY INEFFECTIVE BECAUSE OF COERCION, THE CONDITIONS WHICH MADE IT COERCIVE ALSO MAKE IT UNETHICAL $^{96}$}

It is unlikely that any State at this moment in history would attempt to make it a criminal offense for a person to be mentally ill, or a leper, or to be afflicted with a venereal disease. A State might determine that the general health and welfare require that the victims of these and other human afflictions be dealt with by compulsory treatment, involving quarantine, confinement, or sequestration. But, in the light of contemporary human knowledge, a law which made a criminal offense of such a disease would doubtless be universally thought to be an infliction of cruel and unusual punishment in violation of the Eighth and Fourteenth Amendments. ${ }^{97}$

Such a law would also be unethical. Requiring some form of control over mental illness without deeming the illness itself immoral, however, may not be unethical. There are numerous theories that can describe principles for ethically responsible action in the context of medical interventions and ethically responsible behavior by members of the larger moral community. The majority of these theories fall along a continuum from theories that create principles to consider only the self/individual in determining whether a particular intervention is ethical to theories that create principles that the entire moral community should be considered in choosing the appropriate course of action. After briefly exploring these theories, this Article concludes that all either implicitly or explicitly mandate respect for autonomy of the individual to whom a particular action is attributed. Because failure to obtain valid informed consent under-

96. While Part III of this Article makes the argument that coerced consent in the context of mental illness is unethical, some argue that coercion alone does not imply immorality of an action. See Blocuhe, supra note 38, at 240 ("[T] he conclusion that an influence method constitutes coercion does not by itself imply that the method is morally wrong."). For the purposes of this discussion, the terms morality and ethics or moral and ethical choices essentially will be used interchangeably. If those words are understood based on their original derivation, the word morality (root, "more") refers to one's living their life in conjunction with customs or norms, while the word ethical (root, ethos) refers to living one's life in conjunction with principles of reason. A second formulation of the dichotomy considers morality living one's life according to some principle and reserves ethics to refer to those principles tending to lead to a conception of the good. A final distinction suggests that morality refers to an individual's own assessment of right and wrong while ethics refers to the more general principles and concepts utilized in judging morality. This distinction probably comes closest to the intent with which the words are used here. See Robert P. Rhodes, Health Care Politics, Policy, AND Distributive Justice 287 (Suny Press 1992) ("Morality refers to right or wrong behavior consistent with some ethical principles or authority. Ethics is a higher abstract category, the study of principles from which moral behavior can be judged.").

97. Robinson v. California, 370 U.S. 660, 666 (1962). 
mines the autonomy of the mentally ill individual, it also undermines her moral agency. Respect for moral agency itself requires that such agency not be conditioned on coercively induced medication compliance.

\section{A. Informed Consent Respects the Principle of Autonomy}

Theories of autonomy are varied, but "[v]irtually all theories of autonomy agree that two conditions are essential for autonomy: (1) liberty (independence from controlling influences) and (2) agency (capacity for intentional action)." ${ }^{.98}$ These form the basis for three of the five elements of ethically valid consent: (1) competence, a proxy for "capacity," (2) voluntariness, freedom from "control," $"$ and (3) consent, the "intentional action." ments - (4) disclosure and (5) understanding-refer to informational elements, and are required to deem consent informed. The concept of informed consent, therefore, really respects a more fundamental principle of autonomy. Failure to meet the legal elements of consent due to coercion implies a failure to meet the ethical requirements of consent because coercion undermines the autonomy that is requisite to moral theories of consent. Conditioning one's moral agency on coercively driven compliance with a treatment regimen essentially reflects disrespect for autonomy.

98. BEAUCHAMP \& CHILDRESS, supra note 47 , at 58 .

99. An ethical analysis of the element of voluntariness distinguishes between three kinds of pressure on voluntariness: coercion, influence, and manipulation. Coercion results from employing a severe and credible threat for the purposes of controlling another person. "The threat of force used by some police, courts, and hospitals in acts of involuntary commitment for psychiatric treatment is a typical form of coercion." Id. at 94. As implied in the term "involuntary commitment," such coercive treatment should not be considered voluntary and consensual. Some elements of influence in the "treatment" of psychiatric patients may not rise to the same degree of force as these, but are valid and credible threats utilized to solicit cooperation from a patient, often under the guise of consent. See supra notes 85-94 and accompanying text. These should be considered impermissible pressures that also rise to the level of coercion. Manipulation refers to non-coercive influences that in effect convince an individual to do what the individual in authority desires. This strategy pretends to respect the individual's capacity to choose but may alter the mix of information available to her such that only one choice is likely. Discretion in the disclosure component of consent creates an opportunity for manipulation, e.g. the physician may not disclose certain risks or inflate certain benefits of a particular intervention to make the rational decision appear to be one other than what it actually is. These influences also greatly undermine autonomy and should be dissuaded. The third type of pressure, however, is less likely to undermine autonomy and moral agency. Persuasion may actually advance one's moral autonomy by relying on that individual to make decisions guided by reason, although the individual accepts the decision "through the merit of reasons another person advances." See id. at 94 . In effect, this influence recognizes that the individual's moral agency exists in a moral community with many influences and effects attributed to any particular decision. See infra Part III.C for a consideration of other based ethical theories that may ethically and legally utilize persuasion to help a mentally ill individual make decisions regarding treatment. It should be cautioned, however, that acceptable persuasion rests on the notion that the individual is being made to choose the rational option. Because the effects (and limited benefits) of currently available treatments for mentally ill individuals arguably make the choice not to medicate the rational choice, persuasion in the context of current treatment modalities may not be justified.

100. See BEAUCHAMP \& CHILDRESS, supra note 47 , at 79. 


\section{B. Theories of Biomedical Ethics are Based on Respect for the Individual and Generally Function in Concert with Autonomy.}

Traditional biomedical ethics principles of beneficence, nonmaleficence, justice ${ }^{101}$ and autonomy promote a view of ethical behavior that respects the individual, and a commitment to either provide benefit to, or at the minimum, not to harm the individual. ${ }^{102}$ All of these theories appeal directly or indirectly to the underlying principle of autonomy.

\section{Beneficence}

The principle of beneficence holds that in deciding whether a particular biomedical intervention is ethically appropriate, only actions which will result in good for the patient are ethically desirable. ${ }^{103}$ Because this principle implicitly recognizes the value of the individual, ordinarily, beneficence would support interventions that the individual would also autonomously choose. At times, the principle of beneficence undeniably will conflict with the principle of autonomy. The strong respect for the principle of autonomy, however, generally prohibits making decisions to which an individual has not consented unless the intervention is arguably of immense benefit to the individual and some deficiency of the individual prohibits him from recognizing this benefit and making the rational choice to consent. When the principle of autonomy conflicts with principle of beneficence, then, the principle of autonomy most often prevails. ${ }^{104}$ Given the undeniable risks and questionable benefits of modern medications used to treat mental illness, using coercive measures to induce compliance with medication regimens cannot be concluded to be of benefit to the individual. The principle of beneficence would therefore argue against administration of medication to the patient when valid consent has not been obtained.

\section{Nonmaleficence}

The principle of nonmaleficence argues even more strongly against medicating a mentally ill individual absent valid consent. The principle of nonmale-

101. Depending on how the concept of justice is framed, it may be considered either a "self" or "other" ethical theory. If determining whether a particular intervention was fair to the individual, justice is applied as a self theory. In theories of distributive justice, the principle is more communitarian in nature, endeavoring to allocate risks and benefits equally in the community.

102. For a general discussion of these principles of biomedical ethics, see BEAUCHAMP \& CHILDRESS, supra note 47, at 57-272 (exploring in depth these principles).

103. See id. at 176 (discussing the beneficence principle).

104. There is a real tension between the principles of autonomy and beneficence in the context of medical treatment but a more detailed treatment here goes beyond of the scope of this discussion. For a more complete consideration of this tension, see generally id. at 176-94 (discussing the conflict between paternalistic respect for beneficence and respect for autonomy). 
ficence would reject such treatment on two grounds. First, disrespecting autonomy by not seeking valid consent for treatment creates harm. This violates one formulation of the "do no harm" principle which mandates noninterference with autonomy. ${ }^{105}$ Second, this principle finds unethical any intervention which threatens physical harm to the individual. ${ }^{106}$ Pharmacologic interventions in mental illness risk certain harm to the patient with uncertain benefit. ${ }^{107}$ Respect for nonmaleficence makes coercively sought compliance impermissible because both the process and the intervention threaten harm to the individual.

\section{Justice}

Thirdly, the principle of justice argues against coercing compliance. "Common to all theories of justice is a minimal formal requirement [that]: Equals must be treated equally, and unequals must be treated unequally."108 This principle also argues against ethical acceptance of coercively obtained consent. The autonomy of the mentally ill should be interpreted equally to the autonomy of the non-mentally ill, especially if we expect the mentally ill to be moral agents in the same moral community. On this conception of justice, mentally ill individuals ought to be treated equally with respect to the process of consent. Moral coercion that impacts the consent process beyond what would be allowed in other contexts would treat this population unequally and would therefore be unethical. ${ }^{109}$

\section{Autonomy}

The final principle of bioemedical ethics is respect for autonomy itself. While there are limitations on the scope of autonomy, modern treatment of individuals usually affords great deference to this principle. As autonomy underlies the entire informed consent doctrine, failure to obtain valid consent,

105. See id. at 115 ("Respect for autonomy [is limited to] rules of the form, 'Do not interfere with a person's autonomous choices."').

106. Id.

107. See supra notes 55-81 (describing the particular difficulties of pharmacologic management for mental illness).

108. BEAUCHAMP \& CHILDRESS, supra note 47 , at 227 . What constitutes equality and how unequals are defined depend on different notions of justice. Because we expect individuals with mental illness to be part of the same moral community, however, we must afford the group of individuals with mental illness equal autonomy. In the context of mental illness, equality in decision-making may mandate other distributive justice considerations such as how resources might be allocated to permit equal functioning and decision-making. See id. at 227-50.

109. If anything, the considerations raised in Part II would justify unequal treatment in the opposite direction, namely removing conditions that might be coercive in the context of mental illness that might not appear coercive in other situations. Permitting greater coercion in the context of mental illness, when the population is especially vulnerable to exploitation, however, goes against this conception of justice. 
ultimately undermines autonomy and would therefore be considered unethical. $^{110}$

\section{Beyond Traditional Principles of Biomedical Ethics: Moral Agency in the General Community Still Requires Autonomy}

Traditional principles of ethical treatment in the medical context focus on the effect on the individual patient; more general ethical theories judge ethical behavior in contexts beyond the individual person. Theories of moral agency in the larger community may sometimes require sacrifice of purely individual interests in order to promote a healthy and safe community. These moral systems may adopt rules for efficiency that do not require a consideration of autonomous decision-making in every instance; however, autonomy underlies the formation of these background rules. Moral theories accounting for community considerations include: deontological theories, utilitarian theories, communitarianism, and the ethic of care.

Classic theories of ethics include deontology and utilitarianism. Deontological theories stem from the Kantian philosophy advocating for universal maxims of right or wrong actions. These theories implicitly respect autonomy because the individual must be able to choose to act in accordance with the moral principles advanced in order to be held accountable for his choices. ${ }^{111}$ As a moral maxim, utilizing coercion to induce consent would not be desirable. If willed to be a universal law, coercively obtained consent would permit a number of unspeakable results by undermining the individual's ability to choose a course of action. On a Kantian theory, then, coercion should not be permitted when obtaining consent.

Utilitarianism focuses on the individual as a rational actor and asks that the individual act to maximize overall utility. This theory also mimics many of the requirements of autonomous action. The individual must make his choice based on a calculus of benefit and harm attributed to a particular act. Because the requirement of choice also imbues this theory, the theory implicitly requires autonomy. ${ }^{112}$

110. See supra Part III.A (discussing autonomy as the foundation for the doctrine of informed consent).

111. See generally Immanuel Kant, GROUNDWORK FOR THE METAPHYSICS OF MORALS (Allen W. Wood, ed. and trans., Yale University Press 2002). The classic formulation of Kant's categorical imperative requires that one acts such that what he wills will become universal law. This formulation recognizes that one's choices should be considered in his larger community. The individual, however, must be able to rationally determine the effect of universalization on any particular act and must be able to choose not to act in such a way in order for him to live according to Kant's maxim. These actions require freedom from controlling influences and the capacity to act intentionally, or will his actions.

112. In theory, pure utilitarianism would not find it objectionable in a particular situation to coerce consent from a mentally ill person if utility would be maximized by that action. See generally John Stuart Mill, Utilitarianism (Filiquarian Publishing 2007) (1863). This result is what makes pure utilitarian theories unpalatable. While a full consideration of the merits of utilita- 
More recent theories of communitarian ethics and the ethic of care strongly appeal to the individual's standing in a larger moral community. ${ }^{113}$ The communitarian movement argues that "communal values, the common good, social goals, traditional practices, and cooperative virtues" underlie moral action. ${ }^{114}$ This model is based on a theory of collective utility. Individuals within this community, however, must still be able to conduct themselves freely according to these moral norms. Autonomy remains important to communitarian conceptions of the good. Similar to utilitarian theories, under communitarian theories, coercing consent from mentally ill patients would be ethically permissible if overall utility would be maximized by such an action. On first approximation, it may appear that coercive treatment would maximize utility. The general difficulties faced with utilitarian theory in general, however, will also plague this determination. ${ }^{115}$

Less calculating, utility-maximizing interpretations of relational or "other" based ethical theories include the feminist ethic of care theory, which focuses on the different philosophy that the caregiving role of should play in moral decisions. ${ }^{116}$ Caregivers, under this role, would share the responsibility of the mentally ill individual to prevent harm to the community as a result of her illness, without demanding that the individual coercively consent to treatment in order to have moral standing. The accountability theory is arguably a more general formulation of the ethic of care theory, arguing that not only caregiving expectations, but general expectations that result from the status of relationships mandate accountability. We are in general accountable to others with whom we

rianism is beyond the scope of this discussion, applied utilitarian theory is generally difficult on an act by act basis, at least partially because of this discomfort. Rule utilitarianism attempts to apply the same theory by setting background principles, which if upheld, will maximize the utility of the community. As a general rule, permitting coercion in the consent process would not appear to maximize overall utility. An appropriate rule might be that informed consent should be suspended and individuals with medical conditions held accountable for preventing their ailments from affecting others. Such a principle, however, should probably not require more (or a different kind of sacrifice) from one group with illness, than another. For example, when comparing obligations of epileptics to refrain from an action to keep the public relatively safe (e.g. not driving) to the obligation of the mentally ill individual to actively allow something to happen to his body to protect the same interest (e.g. ingesting a medication with known side effects), it would appear that a disproportionate and unnecessary burden is placed on the mentally ill individual.

113. See generally BEAUCHAMP \& CHILDRESS, supra note 47, at 337-77 (describing different moral theories); the "other" or relationship-based moral theories have some of their philosophical roots in Gauthier's description of the collective action problem for moral choices. See generally David Gauthier, MORALS BY AGREEMENT (1986) (describing a view that a moral community forms collective morals because communities form based upon an agreed basis of cooperation despite the fact that this will not maximize the utility of the individual actor). More recent formulations of relationship-based "other" views reject strict calculation of utility that forms the basis of Gauthier's argument.

114. See BEAUCHAMP \& CHILDRESS, supra note 47 , at 362 . This model is designed on a mostly utilitarian theory.

115. See supra note 112 (describing these difficulties).

116. For a general formula of the ethic of care theory, see CAROL GILLIGAN, IN A DIFFERENT VoICE: PSYCHOLOGICAL THEORY AND WOMEN'S DEVELOPMENT (1982). 
are in relationships and they are correlatively accountable to and for us. ${ }^{117}$ This theory would also allow a sharing of responsibility for keeping the risks inherent to mental illness minimized. ${ }^{118}$ These responsibility sharing views allow the individual with the mental illness to operate as a member of the moral community without surrendering his autonomy completely. ${ }^{119}$

Community-based theories also afford a location for appropriate persuasion, but not coercion, in the informed consent process. Moral persuasion, absent coercion, is not only permissible but may be ethically mandated by communitarian theories. Moral persuasion allows responsible individuals to help a mentally ill individual understand the basis for the morally correct choice. ${ }^{120}$ When the mentally ill individual is competent to make this choice, but perhaps lacks complete understanding of the rationale for the decision, persuasion can be an effective tool in helping the individual realize his moral agency. Still, this moral theory relies on the autonomy of the individual.

\section{CONCLUSION}

Mentaily ill individuals very much want to be members of the moral community in which they live. A mentally ill individual's moral standing in the community, however, does not need to be, and should not be, tied to his conditional acceptance of medication for his condition. Coercing consent for treatment in mentally ill patients legally and ethically invalidates informed consent. Because autonomy provides the ethical principle driving development of the informed consent doctrine, ineffective consent ultimately undermines autonomy. Recognizing that moral agency implicitly requires autonomy, any action which threatens autonomy also threatens moral agency itself. By applying relational theories of ethics, however, the individual can operate in a network of individuals who share accountability for her illness, without requiring the indi-

117. See generally ANITA L. ALLEN, THE NEW Ethics: A GuIDED Tour of the 21st CENTURY MORAL LANDSCAPE 19 (2004). We are generally accountable to the community of which we are a member. Arguments otherwise are suspect unless the individual in question is not a member of the moral community in question.

118. If one sees the ethic of care acting cooperatively with the accountability theory, then the accountability of the individual with mental illness to those with whom he shares relations will not necessarily require him to medicate himself in order to be a member of the moral community.

119. Absent consent to medication that has significant adverse effects, the mentally ill individual may be accountable for his illness in other ways. For example, the individual who chooses not to medicate may choose to live with a family member or in a group environment, in which he can be monitored for periods of deterioration that may require more careful consideration of that individual's choices. The family member may help the mentally ill individual be accountable by helping him attend therapeutic appointments, by making certain dangerous actions less possible, or in the extreme form, by restraining the individual who asks to be restrained to control his irresistible urges. See MiCHEL FoCAULT, ABNORMAL: LECTURES AT THE COLLEGE DE FRANCE 1974-1974 143 (2004).

120. See supra note $94-95$ and accompanying text (detailing the desire of individuals with mental illness to make the correct choice). 
vidual to submit to mental health treatments that may not really be in his best interest. While coercing medical treatment may be necessary in very limited circumstances, ${ }^{121}$ it not should be done under a fiction that the individual has consented. Society, and the accountable individuals, must instead demonstrate the necessity of the action, and must subsequently afford the individual in question due process required for involuntary treatment.

Medication compliance is likely not a general desire of the moral community. Rather, it seems to act as a proxy for the ill individual assuming responsibility for his illness and taking measures to reduce its undesirable effects on others. This expectation comports with moral agency, since the individual must respect others in the moral community in order to be part of that community. Because there are other ways in which this individual can demonstrate respect for others and accountability for his illness, ${ }^{122}$ the individual who chooses these options, though they may be imperfect in practice, should be credited for doing so and afforded a place in the moral community.

It is also important to note that consent absent coercion in the mentally ill patient is valid. If proper steps to eliminate the coercive effects of consent are taken, medication compliance may become an effective proxy for accountability. The worry about the practice of coercion does not disappear, but its impact is less objectionable when the rational decision absent the coercion would lead to the same result. To clarify, in the context of obtaining consent to medicate mentally ill patients, coercion is a particular worry now because the rational choice of the mentally ill individual given his current treatment options may be not to medicate. When treatment options become significantly improved such that the rational person weighing benefits and risks of any particular medication regimen would logically choose to medicate, then there is less practical worry about whether the additional factors of coercion are also present. Although ethically, practices that might be ordinarily considered coercive would still be objectionable, if the individual would arguably make the same decision without the coercive influence, that influence is no longer actually controlling the decision. Thus, if medication compliance is to be restored as a useful proxy to measure moral agency, then developing medications with a better risk to benefit profile should be a major objective supported by the entire moral community.

\section{Man's awareness of himself and of the world about him}

121. It is important to separate arguments of legal "necessity" from ordinary moral acts and choices of a mentally ill individual. It may in fact be necessary to undermine an individual's autonomy in order to minimize particularly significant untoward effects on others. In such situations, the "justice" or "communitarian" accounts of ethics will permit coercive or forcible treatment of mentally ill persons. This, however, should be reserved only for those limited situations in which this option is the only option to protect the life and/or safety of another or the mentally ill individual himself. To act otherwise fails to recognize the mentally ill individual's moral worth.

122. See supra note 119 . Even an agreement to be evaluated, without succumbing to coercive treatment, demonstrates accountability. 
seems to be a steadily expanding one, bringing in its wake an ever large burden of understanding. This burden, then, is to be expected and must not be misinterpreted. Our only rational means for lightening it is more understanding, and appropriate action based on such understanding. ${ }^{123}$

Our failure to better understand the mechanisms of mental illness should not justify failing to afford full moral agency to this population. Respecting their moral agency, however, mandates respecting their autonomy. If the reason to be moral is really because we care, then we ought to care about this as much as anything else.

123. Thomas Szasz, The Myth of Mental Illness, 15 AMERICAN Psychologist 115, 118 (1960). 
